\title{
Editorial
}

\section{Parafibromin as a Tool of Screening in Parathyroid Neoplasms}

Parathyroid carcinoma is the rare malignant form of primary hyperparathyroidism frequently associated with mortal outcome due to uncontrolled hypercalcemia. The diagnosis of benign and malignant parathyroid tumor depends strictly on certain morphological features or histologically documented metastasis. The diagnosis of parathyroid carcinoma thus requires either vascular or perineural invasion, invasive growth into adjacent tissues and/or metastases. The morphological features do not accurately predict the risk of malignancy and the tumor may already be incurable at the time of diagnosis. Therefore, the diagnosis of parathyroid carcinoma is often made in retrospection after surgery or sometimes after relapse.

A category of parathyroid neoplasms of uncertain malignant potential also known as atypical adenoma shows few morphological features suggestive of malignancy but lacks definite criteria of malignancy further adding to the complexity of parathyroid tumors. Sandelin et al ${ }^{1}$ showed that

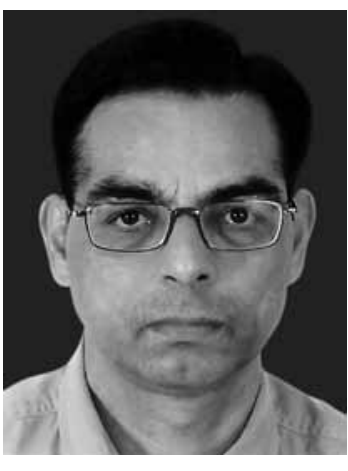
half of the cases that were diagnosed as benign on histology showed recurrence or metastasis later. According to Marsh et al, ${ }^{2,3}$ approximately $50 \%$ of biologically malignant parathyroid tumors are diagnosed as benign by histological criteria, whereas around only $15 \%$ of histologically diagnosed parathyroid carcinomas actually behave biologically in an aggressive manner and rest behave as biologically benign. These tumors may represent either histologically benign tumor mimicking as malignant or malignant tumor being cured by surgical excision. Still there are some parathyroid tumors which are large sized but benign on histology. These tumors have different molecular characteristics that are more similar to malignant tumors. ${ }^{4,5}$

The expression of immunohistochemical (IHC) markers has variable sensitivity and specificity in predicting malignancy due to difference in diagnostic criteria and different cut offs used in published studies. The markers studied include molecules involved in cell cycle proliferation and regulation such as parafibromin, APC, galectin-3, PGP9.5, Ki67, Rb, p53, p27, cyclin D1, FHIT and so on. Some of these markers like parafibromin, APC, PGP9.5 and galectin-3 have shown relatively high but variable sensitivity and specificity. ${ }^{3,6,7}$

The HRPT2 gene was first known to cause sporadic parathyroid carcinoma in $2003 .{ }^{8,9}$ The protein product of this gene, parafibromin, is ubiquitously expressed and functions as tumor suppressor protein. Parafibromin is a nuclear protein that functions as transcription regulator. Its overexpression inhibits cell growth and causes cell cycle arrest at G1 phase partly due to cyclin D1 regulation as shown by Lin et $\mathrm{al}^{10}$ in 2008 . Somatic HRPT2 mutation occurs in $66 \%$ to $100 \%$ of parathyroid carcinomas, resulting in absent expression of parafibromin in atypical adenomas and carcinomas..$^{8,11}$ The sensitivity and specificity of parafibromin has been reported to be $96 \%$ and $99 \%$ respectively in the diagnosis of parathyroid carcinoma by Tan et al. ${ }^{6}$ Absence of parafibromin in adenomas related to HPT-JT syndrome suggests HRPT2 mutation. Gill et al ${ }^{7}$ showed $76 \%$ sensitivity of parafibromin in carcinoma considering complete loss. Howell et al ${ }^{3}$ showed $67 \%$ sensitivity and $100 \%$ specificity for complete loss of parafibromin in parathyroid carcinoma. Thus, absent parafibromin immunoreactivity suggests either parathyroid adenoma or carcinoma with underlying genetic alteration of HRPT2 gene. However, positive parafibromin immunoreactivity strongly suggests benign tumor. ${ }^{8,12}$ According to Brown et al, ${ }^{13}$ presence of parafibromin staining in histologically atypical adenoma confirms a diagnosis of benign adenoma whereas if it is absent, it suggests having some malignant potential. On the contrary in a histologically malignant tumor, presence of parafibromin indicates low grade malignant tumor and absence indicates malignant tumor with more aggressive course. We studied 170 cases of parathyroid lesions including adenoma, carcinoma and atypical adenoma and found a sensitivity of $70 \%$ and specificity of $85.9 \%$ for parafibromin (unpublished data).

Thus, the results of above studies show that sensitivity and specificity of parafibromin is variable. The other issue is that parafibromin is a nuclear stain and nuclear stains are sometimes technically difficult. Therefore, instead of relying on parafibromin as single marker which is expressed in adenomas and negative in carcinomas, it should be combined with panel of markers including a cytoplasmic marker as well as positive markers for carcinoma to improve the sensitivity and specificity of differentiation between adenomas and carcinomas. Parafibromin may be accompanied by PGP 9.5, galectin and APC. The use of panel of IHC markers is important especially in cases of large adenomas (>1-2 gm), adenomas with atypical morphological features and clinically suspected carcinomas. In cases of adenomas even if parafibromin is absent, a close follow-up with serial serum calcium levels should be done. Atypical adenomas and suspected carcinomas with positive parafibromin support benign nature of the lesion and these patients may be relieved off from the worry of carcinoma.

Thus in my opinion, parafibromin along with the above panel of antibodies should be used routinely as a screening tool in all parathyroid neoplasms. It will be complimentary to histological features in differentiating benign and malignant parathyroid neoplasms and will help to segregate cases that need aggressive follow-up. 


\section{References}

1. Sandelin K, Tullgren O, Farnebo LO. Clinical course of metastatic parathyroid cancer. World J Surg 1994 Jul-Aug;18:594-598.

2. Marsh DJ, Hahn MA, Howell VM, Gill AJ. Molecular diagnosis of primary hyperparathyroidism in familial cancer syndromes. Expert Opin Med Diagn 2007 Nov; 1(3):377-392.

3. Howell VM, Gill A, Clarkson A, Nelson AE, Dunne R, Delbridge LW, Robinson BG, Teh BT, Gimm O, Marsh DJ. Accuracy of combined protein gene product 9.5 and parafibromin markers for immunohistochemical diagnosis of parathyroid carcinoma. $\mathrm{J}$ Clin Endocrinol Metab 2009 Feb;94(2):434-441.

4. Sulaiman L, Nilsson IL, Juhlin CC, Haglund F, Höög A, Larsson C, Hashemi J. Endocr Relat Cancer 2012 May 24;19(3):389-407.

5. O'Neal P, Mowschenson P, Connolly J, Hasselgren PO. Large parathyroid tumors have an increased risk of atypia and carcinoma. Am J Surg 2011 Aug;202(2):146-150.

6. Tan MH, Morrison C, Wang P, Yang X, Haven CJ, Zhang C, Zhao P, Tretiakova MS, Korpi-Hyovalti E, Burgess JR, et al. Loss of parafibromin immunoreactivity is a distinguishing feature of parathyroid carcinoma. Clin Cancer Res 2004 Oct 1;10(19):6629-6637.

7. Gill AJ, Clarkson A, Gimm O, Keil J, Dralle H, Howell VM, Marsh DJ. Loss of nuclear expression of parafibromin distinguishes parathyroid carcinomas and hyperparathyroidism-jaw tumor (HPT-JT) syndrome-related adenomas from sporadic parathyroid adenomas and hyperplasias. Am J Surg Pathol 2006;30:1140-1149.

8. Shattuck TM, Valimaki S, Obara T, Gaz RD, Clark OH, Shoback D, Wierman ME, Tojo K, Robbins CM, Carpten JD, et al. Somatic and germ-line mutations of the HRPT2 gene in sporadic parathyroid carcinoma. N Engl J Med 2003 Oct;349(18):1722-1729.

9. Howell VM, Haven CJ, Kahnoski K, Khoo SK, Petillo D, Chen J, Fleuren GJ, Robinson BG, Delbridge LW, Philips J, et al. HRPT2 mutations are associated with malignancy in sporadic parathyroid tumors. J Med Genet 2003 Sep;40(9):657-663.

10. Lin L, Zhang JH, Panicker LM, Simonds WF. The parafibromin tumor suppressor protein inhibits cell proliferation by repression of the cmyc proto-oncogene. Proc Natl Acad Sci USA 2008 Nov 11;105(45):17420-17425.

11. Schantz A, Castleman B. Parathyroid carcinoma. A study of 70 cases. Cancer 1973 Mar;31(3):600-605.

12. Juhlin CC, Villablanca A, Sandelin K, Haglund F, Nordenström J, Forsberg L, Bränström R, Obara T, Arnold A, Larsson C, et al. Parafibromin immunoreactivity: its use as an additional diagnostic marker for parathyroid tumor classification. Endocr Relat Cancer 2007 Jun;14(2):501-512.

13. Brown S, O'Neill C, Suliburk J, Sidhu S, Sywak M, Gill A, Robinson B, Delbridge L. Parathyroid carcinoma: increasing incidence and changing presentation. ANZ J Surg 2011 Jul-Aug;81(7-8):528-532.

Narendra Krishnani MD

Professor, Department of Pathology

Sanjay Gandhi Postgraduate Institute of

Medical Sciences (SGPGIMS)

Lucknow, UP, India 